\title{
Design of Smart Home Energy Management System for Saving Energy
}

\author{
Bilal Mubdir, (MS) \\ Asaad Al-Hindawi, (PhD) \\ Sulaimani Polytechnic University, Iraq \\ Noor Hadi, (MS) \\ University of Technology, Iraq
}

doi: 10.19044/esj.2016.v12n33p521 URL:http://dx.doi.org/10.19044/esj.2016.v12n33p521

\begin{abstract}
The rapid change and development in human life, information technology, and the increase in using home gadgets, modern appliances, and electric cars, leads to more dependency on electrical resources and consecutive increase in $\mathrm{CO} 2$ emission from generation plant. The current world issue is on how to save the energy by reducing the consumption and decreasing global warming. In this research, Smart Home Energy Management System (SHEMS) has been developed to operate home appliances in an optimum approach. It is aimed at reducing the consumption energy by detecting the residents' activity and identifying it among three states: Active, Away, or Sleep. The SHEMS is designed with an algorithm that is based on Hidden Markov Model (HMM) in order to estimate the probability of the home being in each of the above states. The proposed system uses the WiFi technology for data transmission inside home and the GSM technology for external communication. The proposed system and its algorithm was successfully tested and $18 \%$ of energy saving were obtained.
\end{abstract}

Keywords: Microcontroller, GSM, HMM, WiFi, Energy Saving

\section{Introduction}

Nowadays, energy represents the vital need of the human being. With the latest development of technology and the raising usage of the electric cars, energy consumption is increasing day by day. The demand of energy becomes much greater than actual generated energy in almost all countries. Therefore, energy is to be considered as one of the basic infrastructures for the growth of any economy and an essential factor to evaluate the progress of any state or country (Aswani \& Rathan, 2014). According to the impact of energy, energy saving is very essential in reducing the costs of the energy. 
Many technologies were used for residential purposes. These technologies can be categorized into two broad types: power generation systems and solutions to reduce consumption. The first solution could be achieved by installing micro generation system like solar panels or wind turbine at homes, while the second solution is more reliable due to its low cost as compared to the first solution. However, it could be achieved by hiring smart management systems that could schedule the operation of the home appliances by switching off the appliance for an energy saving condition when not in use (Jun Wei Chuah et al., 2010).

Smart system is a term of the new technology that will be found in many applications in our daily lives, for examples, in the field of energy management, medical applications, and industrial automation and automotive. The key subject of smart systems is the new inventions in the fields of nanotechnology, biotechnology, optical technology, advanced materials technology or nano electronics (Manfred Glesner \& Framcois Philipp, 2013).

Modern houses may be equipped with many developed devices, for example, DTVs, personal computers, refrigerators, washing machines, HVAC, heaters etc. Therefore, managing the operation of these appliances in an astute way might result in a notable reduction in energy consumption.

\section{Related Works}

Different approaches of managing the home appliances have been reviewed before going into the proposed approach of this research.

In 2013, Zhao and his colleges introduced the general architecture of energy management system based on the smart grid. In addition, they proposed an efficient scheduling method for home power usage which combine real-time pricing (RTP) with the inclining block rate model. By adopting this combined pricing model, our proposed power scheduling method would effectively reduce both the electricity cost and the power peak-to-average ratio. Consequently, they achieved this adoption by the use of a genetic algorithm to solve the problem of possibility that most appliances would operate during that time. This is used with the lowest electricity price when the RTP model is adopted.

They made an extensive model to manage and schedule the operation of the appliances but depending on the RTP, which is provided by the smart gird. Their system resulted in a reduction in power consumption but was achieved through the use of complex mathematical models.

In 2013, Hyung-Chul Jo et al. studied the smart heating, ventilation and air conditioning scheduling method that considers home resident convenience and characteristics of the thermal device and an optimizationbased approach to minimize the cost in Home Energy Management System 
(HEMS). They described an HVAC model that considers the convenience of the home resident and a method to solve the scheduling problem with a model for HEMS. Thus, they focused their study on temperature control in home. Also, they proposed an algorithm that provides an optimal scheduling of energy resources and avoids inconvenience to the home resident. Furthermore, this resulted to HVAC energy consumption reduction. Their method was expected to reduce the cost for household owners because it can be applied to a variety of home environments.

In 2010, Jiakang Lu et al. also proposed an approach to sense the activity patterns of the home residents. They use these patterns to control the operation of the HVAC system, and automatically turned it off in order to reduce the consumed energy. They identified the activity patterns of the home residents by using Hidden Markove Model. Also, they used the occupancy sensors and the doors statuses parameters to decide which pattern is currently available. They referred to their approach as Smart Thermostat and they evaluate it by deploying occupancy sensors in 8 homes. After then, they compared the results against another traditional approach. They conclude that their approach had achieved a 28\% energy saving on an average for the HVAC system. Their system has considered the HVAC system only and the subjected approach could only be applied for the central HVAC system. Several home uses the split type or individual HVAC systems, especially the small home where this approach cannot be applied. On the other hand, the use of Hidden Markov Model has its advantages in identifying the status of the residents' activity. Thus, this is the same model that was used next in this research proposed system.

In 2011, Makonin and Popowich have proposed a prototype Home Occupancy Agent that determines the occupancy of the home residents by monitoring the power consumption from the energy meter and using ambient light sensor reading. They monitor the power consumption in order to detect the residents' activity by looking for spikes in kilowatt readings which are directly related to the residents turning appliances on and off. Their proposed agent has the ability to determine when the residents are asleep to provide a potential for more energy saving chances. In addition, their proposed agent mainly depends on detecting the spikes of the power consumption readings of the kilowatt meter. This method may require very accurate devices to detect the spikes in addition to its cost.

In 2011, Seong Ho Ju et al. proposed an effective simple scheme to reduce the waste of power in homes. They focused on the energy consumption by developing Home Energy Management System (HEMS) to control the home devices. Their system consists of device agent for each appliance and the whole system works based on the Automatic Meter Reading (AMR) network. However, this is carried out through the use of 
Power Line Communication (PLC). Using their system has resulted in a significant reduction in the energy consumption cost up to $17 \%$. On the other hand, the system structure is valid only if AMR wattmeter is used in the house. However, since their system depends on a remote server located in the electrical utility, an advance network infrastructure should be made available to secure the connection between the HEMS and the utility. This previous issue could be considered as a disadvantage of their scheme due to its complexity and development cost. In spite of obtaining a notable saving in energy consumption, the application of their system is limited to the countries that involves smart grid and advance network infrastructure.

In 2009, Khusvinder Gill et al. explained the available home automation systems and the use of communication technologies. In their research, they integrated the Zigbee technology with Wi-Fi network through one home gateway. They tested their proposed automation system by using four types of different appliances to evaluate the effectiveness of their proposed system. However, this was in spite of the simplicity and flexibility of their proposed system. Thus, they didn't prove the energy saving features of the system, where the only evaluated issues are the control of the appliances remotely through the Zigbee technology.

In 2011, Dange and Gondi described the design of a new generation of home automation system using the Power-Line Communication "PLC" for the local communication purposes. The main features of this system is the web-based control and data logging facility. Their proposed system is cost efficient and does not need more expensive equipment at installation since it reuses the pre-installed power lines to the all home appliances. Nevertheless, there are many limitations when using the PLC. PLC is an old technology used for communication and has many disadvantages like the attenuation, noise. In some cases, repeaters are needed to amplify the communication signal.

In this research, an adaptive algorithm has been proposed to recognize the activity states of home residents and control the operation of the home appliances accordingly. The proposed system mainly depends on employing motion sensors and remote actuators to control the home appliances. However, the system was designed to be able to detect three states: whether the home is occupied by residents inside home and active (Active), or residents are inside home but not active (Sleep), or residents are outside home (Away). According to the detected state of the home, the appliances could operate based on pre-defined schedule for each state. The process of identifying the state of the home among the previously defined states is carried out by monitoring the motion inside the home and the logical status of the main door. 


\section{System Architecture}

The proposed Smart Home Energy Management System (SHEMS) consists of Home Smart Gateway (HSG), Sensing Units (SU), and End Appliance Unit (EAU). Figure (1) shows the essential architecture of the proposed SHEMS.

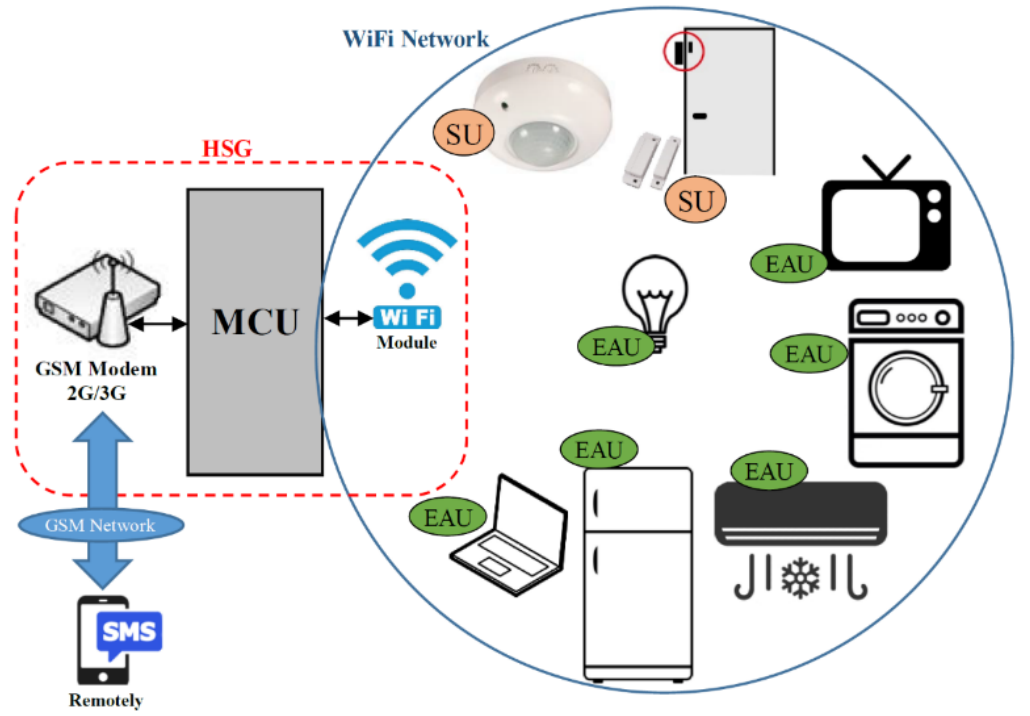

Figure 1. The proposed SHEMS architecture

The proposed system relies on this part. Thus, it represents the gateway of the whole system to the external world. In this part, an adaptive algorithm was designed to be running continuously to elicit scheduled operation for the appliances according to the activity behaviour of the home residents. The HSG is responsible for monitoring all the Sensing Units (Sus) in the home and controlling the End Appliance Units (EAUs). Therefore, the HSG is designed to monitor and control all sensors and appliances through the local Wi-Fi network by using Wi-Fi module. In addition, GSM modem is employed to provide a link between the residents when they are outside the home for monitoring and control purposes. The GSM modem and the WiFi module have been interfaced to Microcontroller Unit (MCU) via UART. The microcontroller used in the proposed system is PIC18F4620 from Microchip Inc. For the WiFi network connection, the ESP8266 module is interfaced to the MCU in HSG and to the other units, EAUs and SUs. On the other hand, SIM900 GSM modem is used to secure the external connection of HSG to the GSM network. Here, the resident could control and monitor any appliance remotely using SMS.

Furthermore, HSG is programmed to have the ability of controlling the operation of lighting for each room separately depending on its motion 
sensor. The lighting of any room is turned OFF as soon as it is not occupied for a specified time (5-10 minutes), where this ability offer more energy saving.

\subsection{End Appliance Unit (EAU)}

This unit simply consists of microcontroller, WiFi module, and electromechanical relay as shown in figure (2). This architecture represents the actuator that controls the operation of the home appliance. The microcontroller used in this unit is ATmega328, which is cost effective with good performance and interface capabilities from Atmel Company. This unit receives the commands from HSG and its main function is to turn ON or OFF the connected appliance. Also, each appliance in the home requires one EAU to make it within the system coverage.

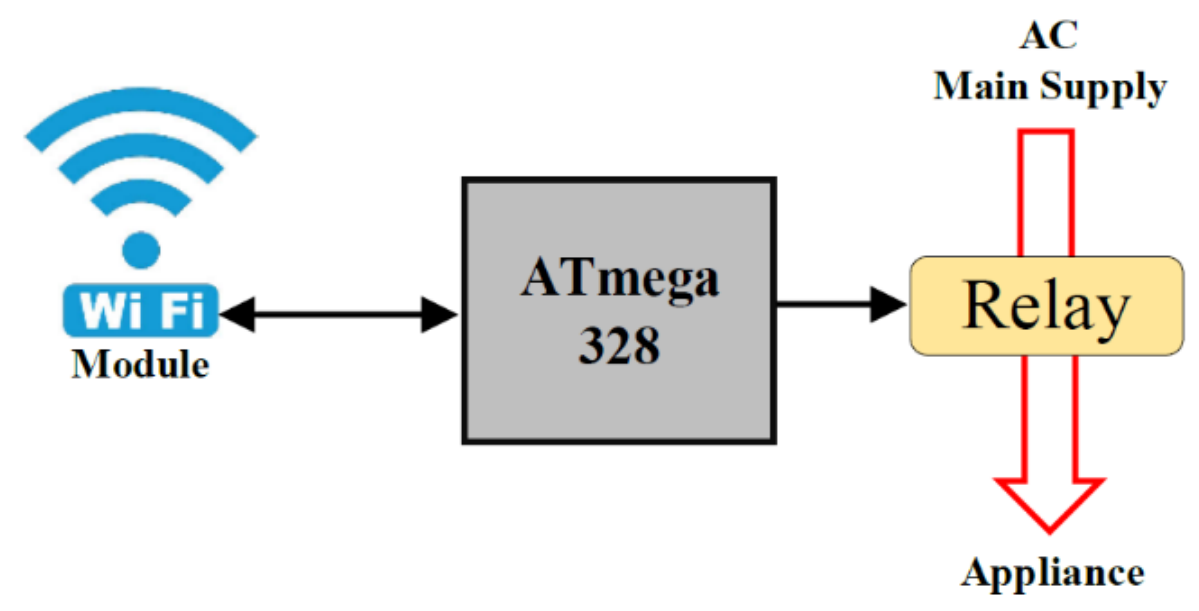

Figure 2. The block diagram of the EAU

\subsection{Sensing Unit (SU)}

Two types of sensing units are used for the proposed system. The first one is to detect the activity of the residents inside the home and a motion sensor is employed in each room. With the aid of MC, any motion in the room will be transferred to the HSG. This SU for each room is composed of PIR Sensor and ATmega328 controller as shown in figure (3a).

On the other hand, the second sensing unit is employed to monitor the status of the main home door. It conveys the status of this door, either open or closed. Magnetic contact switch (door sensor), with Atmega328, are used to construct this SU as shown in figure (3b).

All information collected by SUs and transferred to HSG are required to feed the proposed adaptive algorithm in the present research. 


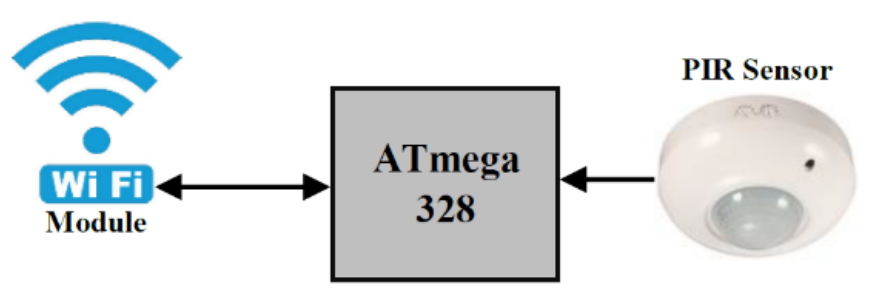

(a)

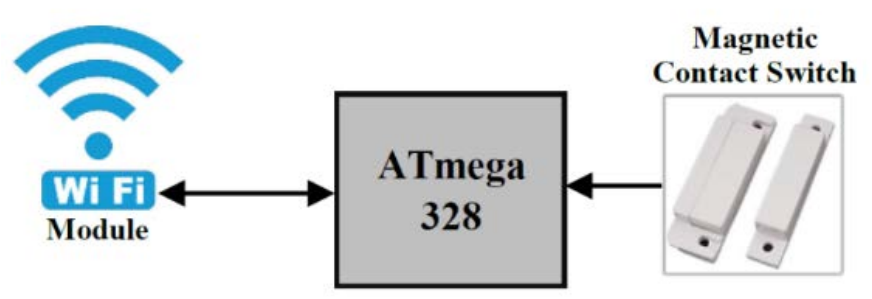

(b)

Figure 3. (a) Block diagram of Motion SU, (b) Block diagram of Door SU.

\section{System Algorithm}

The proposed SHEMS governed by advance algorithm to control the operation of the home appliances based on a pre-defined schedule for each home state is shown in figure (4) below.
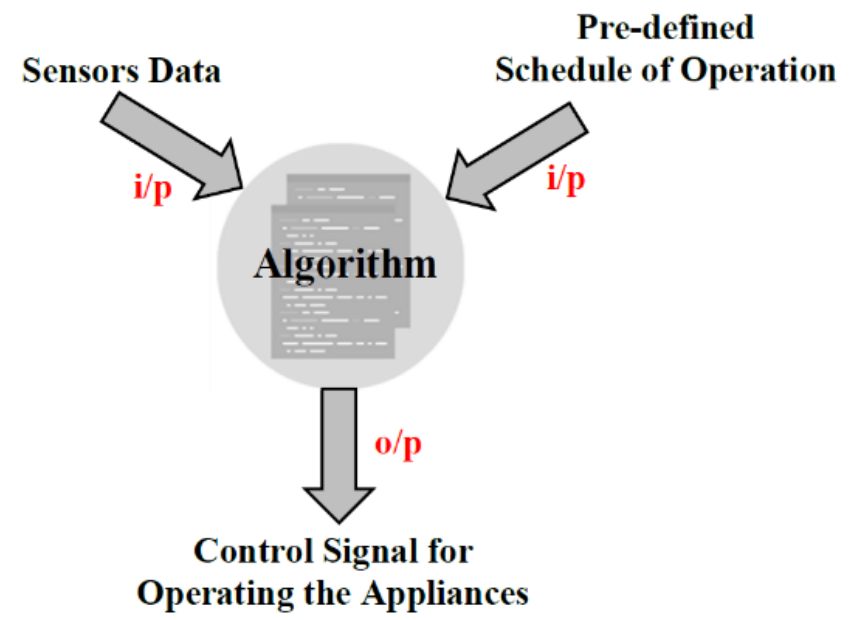

Figure 4. The working principle of the system's algorithm

Subsequently, this algorithm has the ability to identify the state of the home residents, either Active, Sleep, or Away. Hidden Markov Model 
(HMM) has been used to estimate the probability of the home being in each of the above states. This is because it is a popular tool to recognize the generative sequences and it represents probability distribution over sequences of observation (Zoubin Ghahramani, 2001).

The hidden variable in our algorithm $\mathrm{y}_{\mathrm{t}}$ were distributed over the three states of the home (Active, Sleep, and Away).

The observed variable $\mathrm{x}_{\mathrm{t}}$ is a vector of time. Also, sensors data feedback consists of three parameters; (i) measured time $\Delta t$ at specific condition, (ii) total number of the active motion sensors, and (iii) the logical status of the main door. However, HMM is illustrated in figure (5).

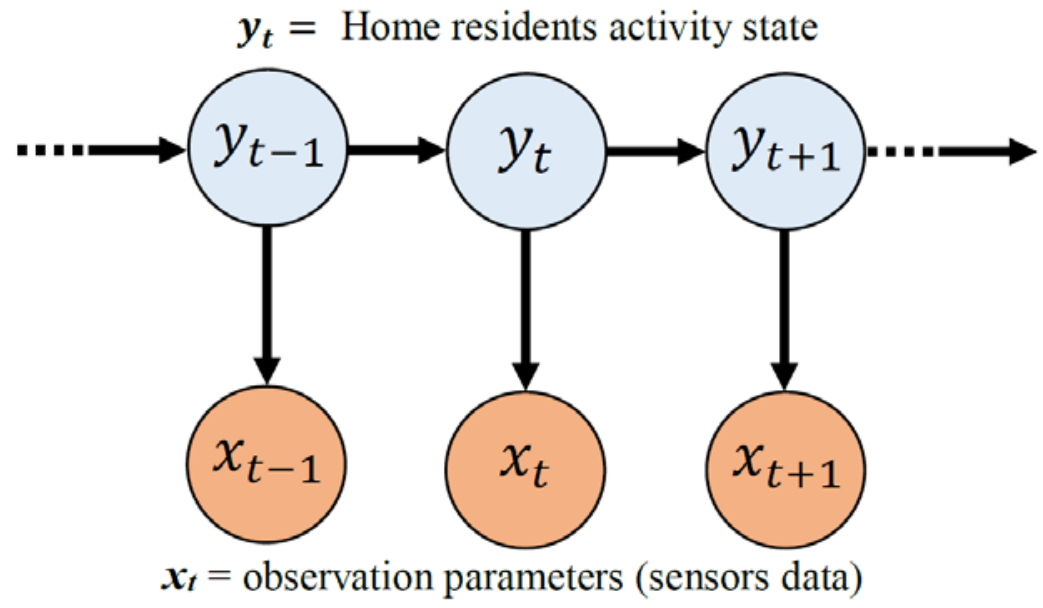

Figure 5. The layout of the HMM

Where,

$\boldsymbol{y}_{\boldsymbol{t}}=$ Hidden variable (state), $\boldsymbol{y}_{\boldsymbol{t}} \in$ (Active, Sleep, Away) $\boldsymbol{x}_{\boldsymbol{t}}=$ Observed variable, $\boldsymbol{x}_{\boldsymbol{t}}=[\Delta t, \lambda, d]$

$\Delta t=$ Measured time for specific action

$\lambda=$ number of the active motion sensors.

$\mathrm{d}=$ logical status of the main door, $\mathrm{d} \in(0,1)$

The logical status of the main door when it is physically closed is normally 0 . Whereas, whenever the door is physically opened and then closed, the status would be changed to 1 for a short time and then changed back to 0 . This short change in the logical status works as a flag to the algorithm for further programming purposes. The algorithm has been structured to estimate and identify the state of residents' activity inside the home. Also, it has changed the state of the home from one state to another state according to the observed variable vector $\left(\mathrm{x}_{\mathrm{t}}\right)$ as shown in figure (6). 


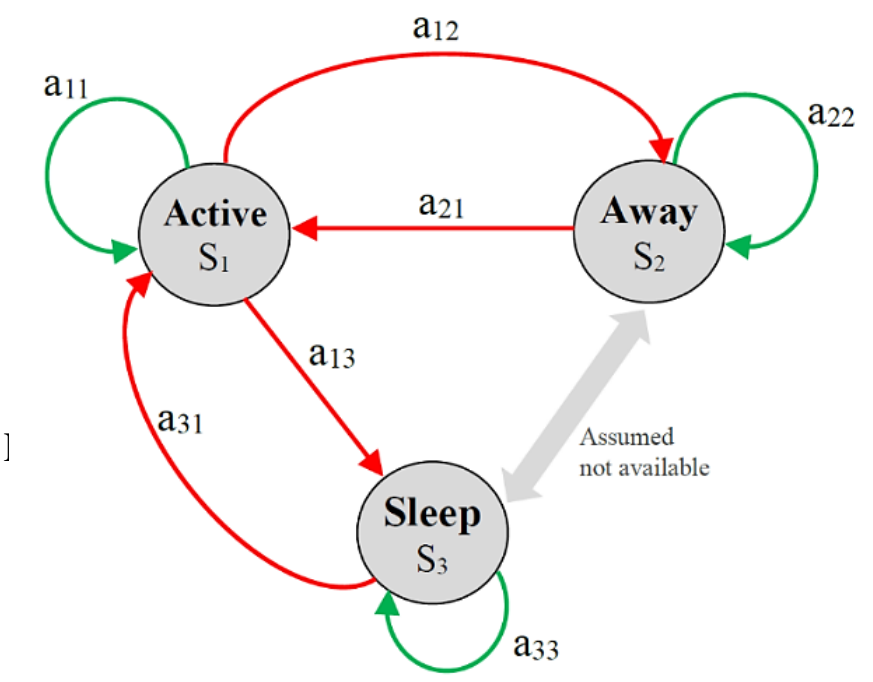

Figure 6. The HMM states for the proposed SHEMS

Table (1) illustrates the condition for each transition according the observed variable vector that mainly depends on sensors feedback.

Table (1). The conditions for state transitions

\begin{tabular}{cccccc} 
Eี & \multicolumn{3}{c}{ Observed Variable } & \multicolumn{2}{c}{$\begin{array}{c}\text { State } \\
\text { Next Estimated } \\
\text { (Hidden) }\end{array}$} \\
$\mathrm{a}_{11}$ & $3 \boldsymbol{t}$ & $\boldsymbol{\lambda}$ & $\boldsymbol{d}$ & Current & Active \\
$\mathrm{a}_{12}$ & $15 \mathrm{~min}$ & 0 & 0 & Active & Away \\
$\mathrm{a}_{13}$ & $15 \mathrm{~min}$ & 0 & 0 & Active & Sleep \\
$\mathrm{a}_{21}$ & $5 \mathrm{~min}$ & $>1$ & 1 & Away & Active \\
$\mathrm{a}_{22}$ & $3 \mathrm{~min}$ & 0 & 0 & Away & Away \\
$\mathrm{a}_{31}$ & $3 \mathrm{~min}$ & $>2$ & 0 & Sleep & Active \\
$\mathrm{a}_{33}$ & $3 \mathrm{~min}$ & 0 & 0 & Sleep & Sleep
\end{tabular}

For example, if the current state is "Active", when the home resident leaves the home, the main door will be opened and then closed. Here, $\mathrm{d}=0$ and the SHEMS triggered and started to measure the time $\Delta t$ for 15 minute.

If no motion sensor is activated throughout this duration $(\lambda=0)$, then the next estimated (hidden) state will be "Away".

The proposed system changes its state to another state or remains on its current state every three minute. Thus, this time is called the transition time. The transition time was not selected randomly. It is assumed as a minimum time to move between two states (a31). The same procedure could be applied to estimate the hidden state for the other cases. 


\section{Case Study}

A house of three bedrooms with dedicated bathrooms, living room, and kitchen was considered as the study case of this research to evaluate the proposed SHEMS and for testing the performance of the suggested algorithm.

The house plan is shown in figure (7), including standard home appliances and lighting fixtures, where the typical power rating and the average consumption time have been used for simulation purposes as shown in Table (2).

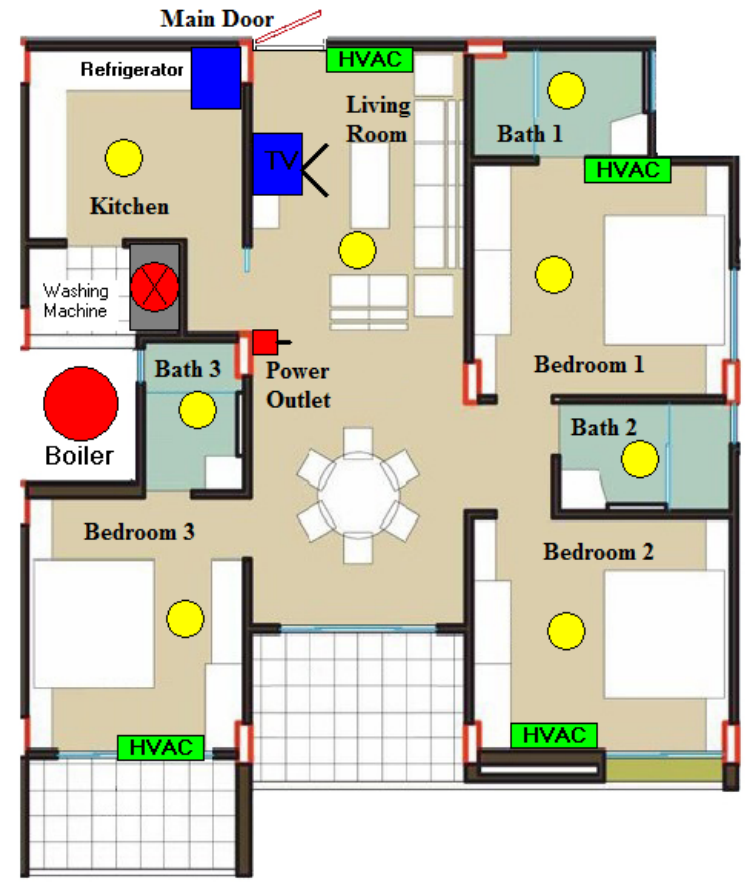

Figure 7. Study case house plan.

Table (2). Power and Average Usage of Appliances

\begin{tabular}{ccc} 
Appliances & $\begin{array}{c}\text { Power } \\
\text { (Watt) }\end{array}$ & $\begin{array}{c}\text { Average Usage } \\
\text { (Hours/Day) [12] }\end{array}$ \\
\hline Phone Charger (socket outlet) & 6 & 24 \\
SU or EAU & 10 & 24 \\
Lighting (per fixture) & 60 & 6 \\
Refrigerator & 300 & 4 \\
TV & 600 & 5 \\
Washing Machine & 1000 & 1.5 \\
HVAC & 1500 & 8 \\
Boiler & 2500 & 7
\end{tabular}


Considering the Power Outlet socket used for charging mobile phone and for each SU or EAU, the estimate power consumption for their circuits is 10 Watt. Here, all the yellow circles are the lighting fixtures of each room.

\section{SHEMS Simulation and Evaluation}

The proposed system is simulated by using Visual Basic application program. Visual Basic has many abilities to test the algorithm with friendly graphical user interface as shown in figure (8).

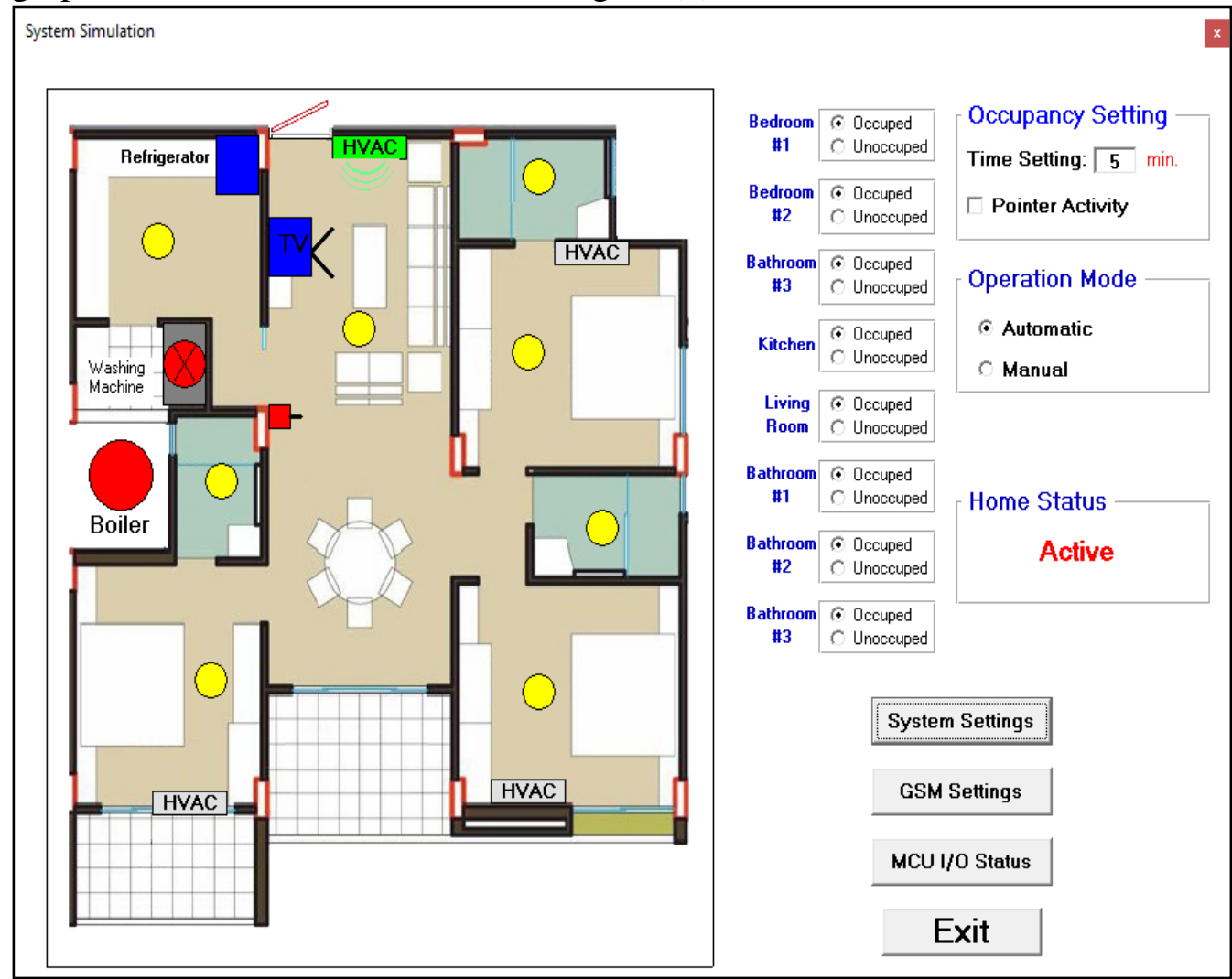

Figure 8. Graphical User Interface of the simulated system

Every appliance was modelled in Visual Basic and was connected to the algorithm. The pre-defined schedule of operation for the home appliances has also been included in the simulation for each state as shown in figure (9). These selections could be changed to test the system at different requirements. However, these setting depend on the residents' convenience and their requirements. 


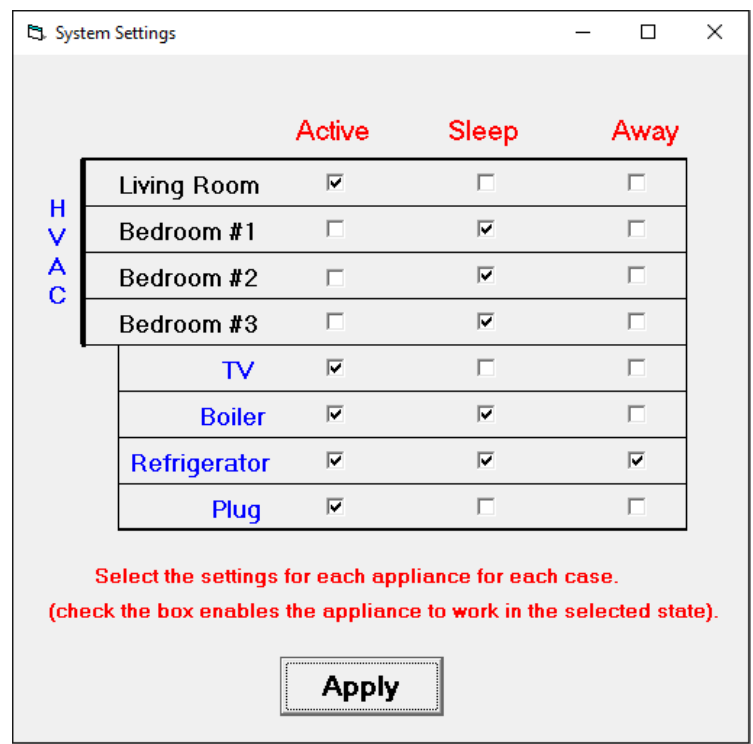

Figure 9. The simulated pre-defined schedule of operation

\section{Tests and Results}

The proposed system had been tested successfully, where the performance of the system tested according to two scenarios. In the first scenario, the home residents are assumed to leave their home from 7:00 AM and return back at 4:00 PM. Then, they are active until 12:00 AM. Whereas the second scenario based on the study of Stephen Makonin and Fred Popowich (2012) have found that for one day (24 hours), home residents are average active for $36.72 \%, 31.15 \%$ sleep, and $32.13 \%$ away. For both scenarios, the pre-defined operation schedule is illustrated in Table (3). Additionally, the two scenarios are explained in Table (4). Therefore, the system was evaluated for three cases, using SHEMS with first scenario, using SHEMS with second scenario, or without SHEMS.

Table (3). Pre-Defined Schedule of Operation

$\begin{array}{cccc}\text { Appliance } & \text { Active } & \text { Away } & \text { Sleep } \\ \text { Phone Charger } & \text { ON } & \text { OFF } & \text { OFF } \\ \text { Refrigerator } & \text { ON } & \text { ON } & \text { ON } \\ \text { TV } & \text { ON } & \text { OFF } & \text { OFF } \\ \text { HVAC (Living Room) } & \text { ON } & \text { OFF } & \text { OFF } \\ \text { HVAC (Bedroom 1) } & \text { OFF } & \text { OFF } & \text { ON } \\ \text { HVAC (Bedroom 2) } & \text { OFF } & \text { OFF } & \text { ON } \\ \text { HVAC (Bedroom 3) } & \text { OFF } & \text { OFF } & \text { ON } \\ \text { Washing Machine } & \text { On request } & \text { On request } & \text { On request } \\ \text { Boiler } & \text { ON } & \text { OFF } & \text { OFF }\end{array}$


Table (4). The two scenarios used for evaluating the system

\begin{tabular}{|c|c|c|c|c|}
\hline & & Active & Away & Sleep \\
\hline \multirow{2}{*}{ First Scenarios } & from & 4:00 PM & 7:00 AM & 12:00 AM \\
\hline & to & 12:00 AM & 4:00 PM & 7:00 PM \\
\hline \multicolumn{2}{|c|}{ Second Scenarios [7] } & $36.72 \%$ & $32.13 \%$ & $31.15 \%$ \\
\hline
\end{tabular}

The normal energy consumption without using the proposed SHEMS has been calculated as shown in Table (5). Here, the energy consumption results of the proposed SHEMS have been obtained based on the two scenarios as shown in Table (6) and (7).

Figure (10) shows graphical comparison between the daily consumption of each appliance for the three cases described previously. The total daily consumed energy for each case is shown in figure (11).

Table (5). The consumed energy calculation without using SHEMS

$\begin{array}{ccccc}\text { Appliance } & \text { Qty } & \begin{array}{c}\text { Rating Power } \\ \text { (Watt) }\end{array} & \begin{array}{c}\text { Total Time } \\ \text { (Hour) }\end{array} & \begin{array}{c}\text { Daily } \\ \text { (kWh) }\end{array} \\ \text { Phone Charger } & 1 & 6 & 24 & 0.144 \\ \text { SU and EAU } & 17 & 10 & 24 & 4.08 \\ \text { Lighting } & 8 & 60 & 6 & 2.88 \\ \text { Refrigerator } & 1 & 300 & 4 & 1.2 \\ \text { TV } & 1 & 600 & 5 & 3 \\ \text { HVAC (Living Room) } & 1 & 1500 & 8 & 12 \\ \text { HVAC (Bedroom 1) } & 1 & 1500 & 8 & 12 \\ \text { HVAC (Bedroom 2) } & 1 & 1500 & 8 & 12 \\ \text { HVAC (Bedroom 3) } & 1 & 1500 & 8 & 12 \\ \text { Washing Machine } & 1 & 1000 & 1.5 & 1.5 \\ \text { Boiler } & 1 & 2500 & 7 & 17.5 \\ & & & \text { Total } & 78.304\end{array}$

Table (6). The consumed energy calculation for the first scenario using SHEMS

$\begin{array}{cccccc}\text { Appliance } & \text { Qty } & \begin{array}{c}\text { Rating Power } \\ \text { (Watt) }\end{array} & \begin{array}{c}\text { Out of } \\ \text { Day (\%) }\end{array} & \begin{array}{c}\text { Duty Cycle } \\ \mathbf{( \% )}\end{array} & \begin{array}{c}\text { Daily } \\ \text { (kWh) }\end{array} \\ \text { Phone Charger } & 1 & 6 & 36.72 & 100 & 0.05 \\ \text { SU and EAU } & 17 & 10 & 100 & 100 & 4.08 \\ \text { Lighting } & 8 & 60 & 67.87 & 25 & 1.95 \\ \text { Refrigerator } & 1 & 300 & 100 & 16.6 & 1.20 \\ \text { TV } & 1 & 600 & 36.72 & 100 & 5.29 \\ \text { HVAC (Living Room) } & 1 & 1500 & 36.72 & 80 & 10.58 \\ \text { HVAC (Bedroom 1) } & 1 & 1500 & 31.15 & 80 & 8.97 \\ \text { HVAC (Bedroom 2) } & 1 & 1500 & 31.15 & 80 & 8.97 \\ \text { HVAC (Bedroom 3) } & 1 & 1500 & 31.15 & 80 & 8.97 \\ \text { Washing Machine } & 1 & 1000 & 6.25 & 100 & 1.50 \\ \text { Boiler } & 1 & 2500 & 67.87 & 30 & 12.22 \\ & & & & \text { Total } & 63.78\end{array}$


Table (7): The consumed energy calculation for the second scenario using SHEMS

$\begin{array}{cccccc}\text { Appliance } & \text { Qty } & \begin{array}{c}\text { Rating Power } \\ \text { (Watt) }\end{array} & \begin{array}{c}\text { Total Time } \\ \text { (Hour) }\end{array} & \begin{array}{c}\text { Duty Cycle } \\ \text { (\%) }\end{array} & \begin{array}{c}\text { Daily } \\ \text { (kWh) }\end{array} \\ \text { Phone Charger } & 1 & 6 & 8 & 100 & 0.05 \\ \text { SU and EAU } & 17 & 10 & 24 & 100 & 4.08 \\ \text { Lighting } & 8 & 60 & 24 & 25 & 2.88 \\ \text { Refrigerator } & 1 & 300 & 24 & 16.6 & 1.20 \\ \text { TV } & 1 & 600 & 15 & 100 & 9.00 \\ \text { HVAC (Living Room) } & 1 & 1500 & 8 & 80 & 9.60 \\ \text { HVAC (Bedroom 1) } & 1 & 1500 & 7 & 80 & 8.40 \\ \text { HVAC (Bedroom 2) } & 1 & 1500 & 7 & 80 & 8.40 \\ \text { HVAC (Bedroom 3) } & 1 & 1500 & 7 & 80 & 8.40 \\ \text { Washing Machine } & 1 & 1000 & 1.5 & 100 & 1.50 \\ \text { Boiler } & 1 & 2500 & 15 & 30 & 11.25 \\ & & & & \text { Total } & 64.75\end{array}$

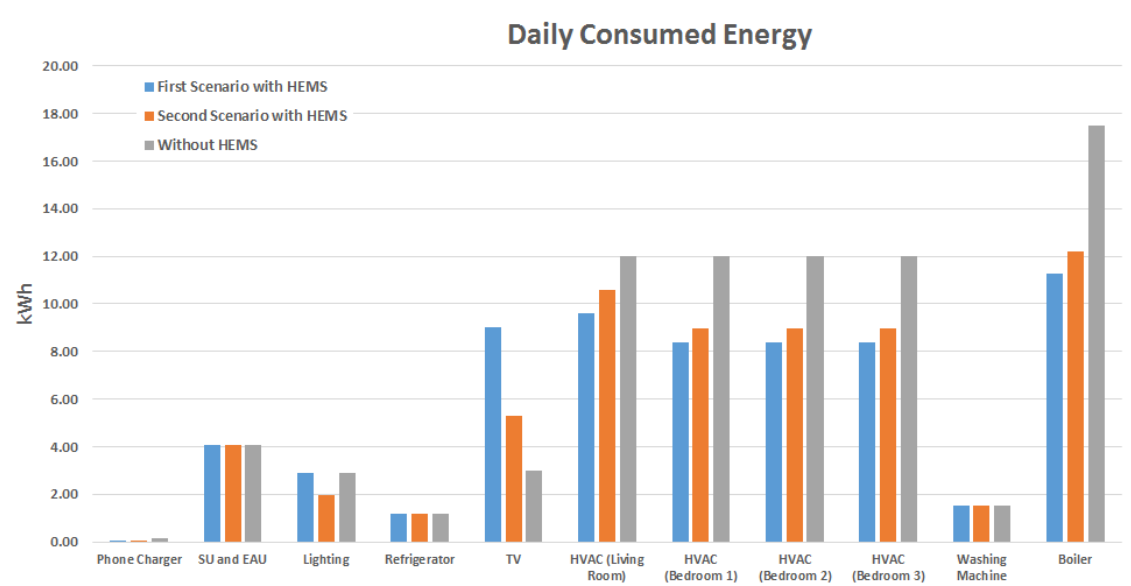

Figure 10. Comparison between the daily consumption of each appliance

\section{Daily Consumed Energy}

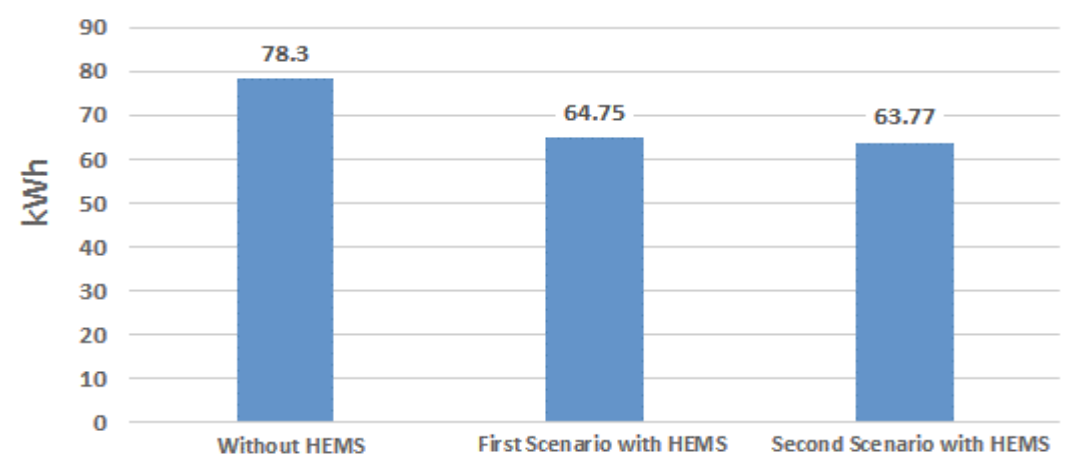

Figure 11. Total daily consumed energy for each case 
The results obviously show the influence of using the proposed HEMS and how it reduces the energy consumption by about $18 \%$. It should be noted that this reduction in consumed energy does not include the energy saving because it utilizes the motion sensors for the lighting inside the home. Furthermore, the system response for receiving SUs data and controlling the appliances through EAUs is within 1-2 seconds. This response time is acceptable since the services of energy management system is classified as a service that requires non-real time property (AnkitChugh, 2014).

\section{Conclusion}

Employing the home management system enrich energy saving without adding expensive equipment or annoying the connivance of home residents. In countries like Iraq and many other countries, conventional national grid is still being used without any ability to control the consumer's home appliances. The proposed SHEMS in this research help to provide a suitable method to add an adaptive method for saving energy up to $18 \%$. The system was designed by using the most contemporary and cheap technology with a simple architecture. The proposed SHEMS provides feedback of the home appliances for the residents so he/she can be able to monitor the home from anywhere via SMS. Thus, it makes them to feel more secure. The proposed algorithm can incorporate another feature to detect the security issues inside the home when the residents are away. However, this feature could be considered as a future work for the proposed SHEMS.

\section{References:}

1. AnkitChugh (2014). Window AC Price List and Power Consumption Comparison (Air Conditioners), Online Review Center, India

2. Aswani C. \& Rathan N. (2014). "Home Energy Management System for High Power Intensive Loads”, Emerging Trends in Electrical, Electronics \& Instrumentation Engineering: An International Journal (EEIEJ), Vol. 1, No. 2.

3. Electricity Demand, Online Energy Resources, Online Electropedia, Woodbank Communications Ltd, UK.

4. H. C. Jo, S. Kim and S. K. Joo (2013). "Smart heating and air conditioning scheduling method incorporating customer convenience for home energy management system," in IEEE Transactions on Consumer Electronics, vol. 59, no. 2, pp. 316-322.

5. H. V. Dange and V. K. Gondi (2011). "Powerline Communication Based Home Automation and Electricity Distribution System," International Conference on Process Automation, Control and Computing (PACC), Coimbatore, pp. 1-6. 
6. Jiakang Lu, Tamim Sookoor, Vijay Srinivasan, Ge Gao, Brian Holben, John Stankovic, Eric Field, and Kamin Whitehouse (2010). The smart thermostat: using occupancy sensors to save energy in homes. In Proceedings of the 8th ACM Conference on Embedded Networked Sensor Systems (SenSys '10). ACM, New York, NY, USA, 211-224.

7. Jun Wei Chuah, AnandRaghunathan and Niraj K. Jha (2010). “An Evaluation of Energy-Saving Technologies for Residential Purposes”, IEEE.

8. K. Gill, S. H. Yang, F. Yao and X. Lu (2009). "A zigbee-based home automation system," in IEEE Transactions on Consumer Electronics, vol. 55, no. 2, pp. 422-430.

9. K. Suzuki and M. Inoue (2011). "Home network with cloud computing for Home Management," IEEE 15th International Symposium on Consumer Electronics (ISCE), Singapore, pp. 421425.

10. Manfred Glesner and Framcois Philipp (2013). “Embedded Systems Design for Smart System Integration”, IEEE Computer Society Annual Symposium on VLSI.

11. www.mpoweruk.com/electricity_demand.htm

12. www.reviewcenter.in

13. Seong Ho Ju, Yong Hoon Lim, Moon Suk Choi, Jong-Mock Baek and Sang-Yeom Lee (2011). "An efficient home energy management system based on Automatic Meter Reading," IEEE International Symposium on Power Line Communications and Its Applications (ISPLC), Udine, pp. 479-484.

14. Stephen Makonin \& Fred Popowich (2012). "Home Occupancy Agent: Occupancy and Sleep Detection”, GSTF Journal on Computing (JoC), VOL. 2, NO. 1.

15. Z. Zhao, W. C. Lee, Y. Shin and K. B. Song (2013). "An Optimal Power Scheduling Method for Demand Response in Home Energy Management System," in IEEE Transactions on Smart Grid, vol. 4, no. 3, pp. 1391-1400.

16. Zoubin Ghahramani (2001). An introduction to hidden Markov models and Bayesian networks. In Hidden Markov models. World Scientific Series In Machine Perception And Artificial Intelligence Series, Vol. 45. World Scientific Publishing Co., Inc., River Edge, NJ, USA 9-42. 